\title{
Dampak Mediasi Earnings Management pada Pengaruh Tournament Incentives terhadap Kemungkinan Terjadinya Fraud dalam Laporan Keuangan
}

\author{
Hidayatul Khusnah \\ Prodi S1 Akuntansi Fakultas Ekonomi dan Bisnis \\ Universitas Nahdlatul Ulama Surabaya \\ e-mail: hidayatul.khusnah@unusa.ac.id
}

\begin{abstract}
This study aims to investigate the effect of tournament incentives on earnings management and fraud, as well as the mediating impact of earnings management on the effect of tournament incentives on fraud. This research was conducted in manufacturing companies listed on the Indonesia Stock Exchange (IDX) which publish annual financial reports for six consecutive years, starting from 2014 to 2019. The data in this study were obtained from the official website of the Indonesia Stock Exchange (www. idx.co.id), the website of each company, www.ahamok.com. The data analysis technique in this study used SEM-PLS analysis using the WarpPLS 5.0 software. The results of this study indicate that tournament incentives have a positive effect on the possibility of fraud in financial reports and earnings management. This study also found a positive effect of earnings management on the possibility of fraud in financial statements. Finally, this study did not find a mediating effect of earnings management on the effect of tournament incentives on the possibility of fraud in the financial statements.
\end{abstract}

Key words: tournament incentives, earnings management, fraud

\section{PENDAHULUAN}

Teori turnamen berkembang sebagai cara untuk menjelaskan kesenjangan upah yang besar antara CEO dan eksekutif peringkat bawah yang biasa diamati dalam praktik dan menjadi perhatian media yang cukup besar (Haß, Müller, and Vergauwe 2015). Kesenjangan upah yang besar akan menjadi informasi yang buruk bagi investor. Selain itu, kesenjangan upah juga berdampak pada kecemburuan sosial yang dapat memicu terjadinya kecurangan.

Teori keagenan menyatakan manajer cenderung mementingkan tujuan pribadi dibandingkan dengan tujuan perusahaan (Jensen dan Meckling, 1976), hal tersebut mendasari terjadinya kecurangan dalam laporan keuangan. Ketika peluang muncul, eksekutif di posisi kunci pengambilan keputusan sangat mungkin untuk memanipulasi laporan keuangan karena secara langsung dapat memengaruhi kekayaan pribadi mereka (Zhang et al., 2008).

Salah satu skema solusi untuk mengatasi hal tersebut adalah dengan cara merancang kompensasi eksekutif (Lazear dan Rosen, 1981; Guay, 1999; Kale et al., 2009; Kubick dan Masli, 2016; \& Sun et al., 2019). Kebijakan kompensasi perusahaan dapat berpengaruh secara signifikan terhadap perilaku manajerial dan kinerja perusahaan Jia (2018). Namun beberapa penelitian terdahulu menunjukkan bahwa skema kompensasi eksekutif tidak selalu berhubungan dengan kinerja perusahaan (Bebchuk and Fried, 2003 yang dikutip oleh Sun et al., 2019). Lazear dan Rosen (1981) menawarkan alternatif bentuk pengaturan kompensasi turnamen yang berbentuk peringkat, turnamen ini memfasilitasi persaingan antara eksekutif senior yang mampu mencapai tujuan maka akan mendapat imbalan berupa moneter dan jabatan. 
Teori tentang turnamen dikembangkan oleh Lazear dan Rosen (1981) yang kemudian diperluas oleh Rosen (1986). Teori ini menyatakan bahwa tournament incentives memfasilitasi persaingan antara eksekutif senior, hanya yang terbaik saja yang akan mendapatkan imbalan moneter yang besar, serta posisi superior dalam hierarki perusahaan. Terdapat ketidakkonsistenan dari penelitian-penelitian sebelumnya terkait dengan tournament incentives, yang mana terdapat dua hasil yang saling bertentangan. Pertama, tournament incentives menyebabkan perilaku negatif manajerial untuk kepentingan pribadi. Beberapa penelitian seperti yang dilakukan oleh (Kini dan Williams, 2012) menunjukkan bahwa tournament incentives dapat mengarah kepada pengambilan risiko manajerial yang lebih besar, Harbring dan Irlenbusch (2012) juga menemukan bahwa tournament incentives dapat menyebabkan kecenderungan kesalahan yang lebih tinggi dalam pelaporan keuangan, selain itu juga menyebabkan fraud dalam keuangan (Haß et al., 2015). Jia (2018) juga menemukan bahwa kesenjangan upah CEO dengan eksekutif senior lainnya juga berpengaruh positif terhadap risiko jatuhnya harga saham di masa yang akan datang. Tournament incentives yang tinggi menyebabkan eksekutif senior cenderung tergoda untuk melakukan perilaku tidak etis dalam menjalankan pekerjaannya sehingga berpengaruh terhadap harga saham di masa yang akan datang.

Kedua, yaitu hasil penelitian yang memiliki hasil bertolak belakang dengan hasil yang pertama, yakni hasil yang menunjukkan bahwa tournament incentives berpengaruh positif terhadap kinerja perusahaan (Kale et al., 2009). Persaingan untuk mendapatkan insentif yang tinggi membuat para eksekutif senior lebih bekerja keras sehingga berdampak positif terhadap kinerja perusahaan. Hal tersebut juga didukung oleh penelitian baru-baru ini yaitu yang dilakukan oleh Sun et al. (2019) menunjukkan bahwa tournament incentives berpengaruh negatif terhadap risiko jatuhnya harga saham.

Penelitian ini bertujuan untuk menginvestigasi pengaruh tournament incentives dan earnings management terhadap kemungkinan terjadinya fraud laporan keuangan. Selain itu, penelitian ini juga menginvestigasi efek mediasi earnings management pada pengaruh tournament incentives terhadap kemungkinan fraud pada laporan keuangan. Penelitian tentang insentif turnamen telah diteliti oleh penelitian sebelumnya di beberapa negara, tetapi belum pernah diteliti di Indonesia. Sun et al. (2019) meneliti insentif turnamen di Negara China, Callen and Fang (2015), dan Jia (2018) meneliti insentif turnamen di Amerika. Alasan peneliti melakukan penelitian tentang insentif turnamen di Indonesia karena di Indonesia memiliki karakteristik yang hampir sama dengan China dan penelitian ini bertujuan untuk menggeneralisasikan hasil penelitian yang dilakukan oleh Sun et al. (2019).

Penelitian ini diharapkan mampu memberikan manfaat bagi para pengambil keputusan, terutama CEO agar lebih objektif dalam memeriksa hasil pelaporan keuangan dari manajer di bawahnya. Manfaat yang kedua untuk memberikan tools bagi CEO untuk melakukan audit internal hasil kinerja bawahannya. Selanjutnya, penelitian ini diharapkan menambah literatur tentang tournament theory sehingga dapat memperluas konsep-konsep dalam tournament theory.

\section{LANDASAN TEORI DAN PENGEMBANGAN HIPOTESIS}

\section{Agency Theory (Teori Keagenan)}

Agency theory atau teori agensi mencoba untuk menjalin hubungan yang formal antara prinsipal dan agen atau pihak-pihak yang berke- 
pentingan dalam proses penyusunan budget. Teori ini menekankan pada perancangan pengukuran prestasi dan imbalan yang diberikan agar para manajer berperilaku positif atau menguntungkan perusahaan secara keseluruhan.

Teori keagenan menjelaskan tentang pemisahan antara fungsi pengelolaan (oleh manajer) dengan fungsi kepemilikan (oleh pemegang saham) dalam suatu perusahaan. Hubungan agensi ini muncul ketika satu atau lebih orang mempekerjakan orang lain untuk memberikan jasa dan kemudian mendelegasikan wewenang pengambil keputusan kepada agen tersebut. Tujuan dari manajer dan pemegang saham sama, yaitu meningkatkan nilai perusahaan melalui peningkatan kemakmuran pemegang saham. Akan tetapi, sering kali manajer tidak selalu bertindak demi kepentingan pemegang saham atau melakukan tindakan yang bertentangan dengan keinginan pemegang saham sehingga terjadi konflik antara manajer perusahaan dengan pemegang sahamnya.

\section{Tournament Incentives}

Teori turnamen dikembangkan oleh Lazear dan Rosen (1981) yang kemudian diperluas oleh Rosen (1986). Teori ini menyatakan bahwa insentif turnamen memfasilitasi persaingan antara eksekutif senior dan hanya yang terbaik saja yang akan mendapatkan imbalan moneter yang besar serta posisi superior dalam hierarki perusahaan.

Di bawah skema turnamen, kinerja eksekutif sering dievaluasi dengan membandingkan seberapa baik kinerja masing-masing eksekutif dibandingkan dengan yang eksekutif lainnya yang ikut dalam persaingan (Sun, Habib, and Huang 2019). Dengan demikian, eksekutif senior yang telah mencapai target yang ditetapkan maka dia yang akan memenangkan persaingan. Eksekutif senior yang memenangkan persaingan akan mendapat insentif berupa moneter dan promosi posisi strategis. Untuk memenangkan persaingan, eksekutif senior harus bisa mencapai target yang telah ditetapkan, tidak jarang dalam proses pencapaian target tersebut para eksekutif senior melakukan perilaku tidak etis.

\section{Earnings Management}

Earning management adalah tindakan campur tangan manajemen dalam proses pelaporan keuangan eksternal dengan tujuan untuk menguntungkan dirinya sendiri. Scott (2003:369) mendefinisikan earnings management sebagai "the choice by a manager of accounting policies so as to achieve some specific objective" yang kurang lebih memiliki arti pilihan yang dilakukan oleh manajer dalam menentukan kebijakan akuntansi untuk mencapai beberapa tujuan tertentu.

\section{Financial Statement Fraud}

Financial statement fraud pada keuangan perusahaan mengacu pada kesalahan pada penyajian dan pengungkapan yang dilakukan secara sengaja di dalam laporan keuangan (Apostolou et al., 2000). Kesalahan penyajian dalam pelaporan keuangan di sini mengandung arti bahwa keputusan pengguna laporan keuangan akan terpengaruh oleh ketidakakuratan informasi salah saji tersebut sehingga akan berpengaruh pula pada keputusan yang diambil.

Terdapat dua jenis kecurangan akuntansi, yaitu kecurangan pelaporan keuangan (fraudulent financial report) dan penggelapan aktiva (misappropriation). Kecurangan pelaporan keuangan merupakan kesalahan penyajian, penghilangan suatu jumlah tertentu atau pengungkapan salah saji secara sengaja dengan tujuan untuk menipu sehingga informasi yang disajikan menyesatkan bagi para pengguna laporan keuangan. 
Sedangkan penggelapan aktiva merupakan kecurangan yang menyangkut pencurian terhadap aset atau entitas perusahaan. Pencurian ini umumnya dilakukan oleh karyawan dengan jumlah yang relatif kecil dan tidak material. Namun pencurian tersebut juga dapat melibatkan manajemen yang lebih dapat menutupi atau menyembunyikan kecurangan sehingga sulit dideteksi (Hery, 2016).

\section{PENGEMBANGAN HIPOTESIS}

\section{Tournament Incentives dengan Earnings Man- agement dan Fraud}

Sekelompok eksekutif biasanya bekerja sama dalam sebuah tim dalam perusahaan yang sudah besar (Jia 2018). Kelompok tersebut terdiri dari CEO dan eksekutif non-CEO yang memiliki tingkatan insentif yang relatif berbeda. Perbedaan insentif antara CEO dan eksekutif non-CEO akan berpengaruh terhadap perilaku manajerial (Bebchuk, Cremers, and Peyer 2011). Eksekutif non-CEO akan merespons positif adanya insentif berbasis kinerja dan berbasis promosi, karena ada peluang untuk dipromosikan menjadi CEO, sedangkan CEO akan menanggapi secara eksklusif hanya untuk insentif berbasis kinerja saja (Kubick and Masli 2016). Eksekutif non-CEO yang memiliki kinerja baik, akan memiliki kesempatan untuk dipromosikan menjadi CEO dengan tambahan insentif yang besar (Lazear and Rosen 2002). Hal tersebut akan memicu terjadinya kesenjangan insentif antara CEO dengan eksekutif non-CEO sehingga insentif turnamen menjadi semakin kuat (Kim, Wang, and Zhang 2016).

Tournament incentives mendorong eksekutif untuk meningkatkan kinerjanya agar mampu mencapai insentif yang ditawarkan. Untuk men- capai target tersebut, tidak jarang para eksekutif melakukan tindakan menyimpang, seperti fraud dalam pelaporan keuangan sehingga dapat berakibat buruk bagi perusahaan. Beberapa penelitian terdahulu yang disimpulkan oleh $\mathrm{Haß}$, Müller, and Vergauwe, (2015) menunjukkan bahwa insentif turnamen mendorong pada pengambilan risiko yang lebih tinggi. Berdasarkan penelitian terdahulu dan argumen tersebut maka hipotesis yang diajukan dalam penelitian ini adalah sebagai berikut.

H1: Tournament incentives berpengaruh positif terhadap kemungkinan terjadinya fraud

$\mathrm{H} 2$ : Tournament incentives berpengaruh positif terhadap kemungkinan terjadinya earnings management

\section{Earnings Management dengan Fraud}

Earnings management adalah tindakan campur tangan manajemen dalam proses pelaporan keuangan eksternal dengan tujuan untuk menguntungkan dirinya sendiri. Scott (2003:369) mendefinisikan earnings management sebagai the choice by a manager of accounting policies so as to achieve some specific objective yang kurang lebih memiliki arti pilihan yang dilakukan oleh manajer dalam menentukan kebijakan akuntansi untuk mencapai beberapa tujuan tertentu.

Persediaan adalah salah satu dari akun termudah untuk dimanipulasi (Stice 1991), karena persediaan memerlukan estimasi subjektif yang dapat berbeda di setiap perusahaannya, yang membuat audit atas persediaan menjadi lebih susah. Persons (1995) menemukan bahwa perusahaan yang curang cenderung memiliki rasio persediaan/total aset yang lebih besar dibanding perusahaan yang tidak melakukan kecurangan. H3: Earnings Management berhubungan positif terhadap kemungkinan terjadinya fraud 


\section{Earnings Management Memediasi Pengaruh} Tournament Incentives terhadap Fraud

Tournament incentives memiliki kecenderungan efek disfungsional yang tidak diinginkan (Jia 2018). Beberapa penelitian terdahulu mendokumentasikan efek negatif dari insentif turnamen, di antaranya terjadinya misreporting dalam laporan keuangan karena eksekutif memanipulasi laporan keuangan demi mendapatkan promosi sebagai CEO (Chena, Honga, and Jeremy C. Stein 2001), memicu terjadinya Fraud dalam pelaporan keuangan (Haß, Müller, and Vergauwe 2015), dan cenderung meningkatkan risiko jatuhnya harga saham (Jia 2018). Earnings management tindakan campur tangan manajemen dalam proses pelaporan keuangan eksternal dengan tujuan untuk menguntungkan dirinya sendiri. Eksekutif senior yang berada dalam kompetisi tidak jarang akan melakukan tindakan earnings management untuk tujuan pribadi yaitu untuk memenangkan persaingan dalam turnamen sehingga dapat berpotensi terjadi fraud.

$\mathrm{H} 4$ : Earnings management memediasi pengaruh tournament incentives terhadap kemungkinan terjadinya fraud

\section{METODE PENELITIAN}

Populasi dalam penelitian ini adalah perusahaan manufaktur yang terdaftar di Bursa Efek Indonesia (BEI) tahun 2013 sampai dengan tahun 2018. Sampel dalam penelitian ini adalah perusahaan manufaktur yang terdaftar dalam Bursa Efek Indonesia (BEI) yang memublikasikan laporan keuangan tahunan selama enam tahun berturut-turut, terhitung mulai tahun 2014 sampai dengan tahun 2019. Data dalam penelitian ini diperoleh dari situs resmi Bursa Efek Indonesia (www.idx.co.id), situs masing-masing perusahaan, www.ahamok.com.

\section{VARIABEL PENELITIAN}

\section{Tournament Incentives}

Variabel tournament incentives diproksikan menjadi gap pembayaran eksekutif. Gap pembayaran eksekutif dalam penelitian ini diukur menggunakan pengukuran Log (CEO-MedianVP Pay) yang juga digunakan oleh peneliti sebelumnya yaitu (Kini and Williams 2012) and (Jia 2018). Gap pembayaran eksekutif diukur menggunakan perbedaan antara total kompensasi (selisih antara jumlah kompensasi jangka pendek dan jangka panjang) dari CEO perusahaan dan nilai median dari total kompensasi yang diberikan tahunan oleh perusahaan.

\section{Earnings Management}

Variabel earnings management diukur dengan menggunakan accrual model yang dikembangkan oleh Jones (1991). Berikut adalah model akrual tersebut.

$$
\begin{aligned}
T A_{i \ell} / A_{i t-1}= & \alpha_{i}\left[1 / A_{i t-1}\right]+\beta_{1 i}\left[\Delta R E V_{i t} / A_{i t-1}\right] \\
& +\beta_{2 i}\left[P P E_{i t} / A_{i t-1}\right]+\epsilon_{i \ell}
\end{aligned}
$$

Keterangan:

$\mathrm{TA}_{\mathrm{it}}=$ Total Accruals in year $\mathrm{t}$ for firm $\mathrm{i}$

$\Delta \mathrm{REV}_{\mathrm{it}}=$ revenues in year $\mathrm{t}$ less revenues in years $\mathrm{t}-1$ for firms i

$\mathrm{PPE}_{\mathrm{it}}=$ Gross Property, Plant, and equipment in year $\mathrm{t}$ for firm i

$\mathrm{A}_{\mathrm{it}-1}=$ Total Assets in year $\mathrm{t}-1$ for firm $\mathrm{i}$

\section{Financial Statement Fraud}

Variabel financial statement fraud dalam penelitian ini diukur menggunakan $\mathrm{M}$ score model yang dikembangkan oleh Beneish (1999) menggunakan variabel dummy dengan dua kategori, yaitu 1 jika perusahaan dianggap melakukan kecurangan pada pelaporan keuangan dan 0 jika perusahaan dianggap tidak melakukan kecu- 
rangan pada pelaporan keuangan. Nilai tersebut berasal dari hasil perhitungan $\mathrm{M}$ score dengan kategori jika hasil penghitungan $\mathrm{M}$ score $>-2,22$ maka perusahaan dianggap melakukan kecurangan pada pelaporan keuangan. M Score terdiri dari delapan indicator yaitu DSRI, GMI, AQI, SGI, DEPI, TATA, SGAI, dan LVGI.

Berikut ini adalah rumus $\mathrm{M}$ score menurut Beneish (1990).

M Score $=-4,840+0,920$ DRSI $+0,528$ GMI $+0,404 \mathrm{AQI}+0,892 \mathrm{SGI}+0,115 \mathrm{DEPI}-$ 0,172 SGAI - 0,327 LVGI + 4,697 TATA

\section{Day's Sales in Receivable Index (DSRI)}

Variabel ini merupakan rasio perbandingan antara penjualan dan piutang dari tahun pertama dan tahun kedua, mengukur apakah antara pendapatan dan piutang mengalami keseimbangan selama dua tahun berturut-turut. Berikut rumus perhitungan rasio DSRI berdasarkan Beneish (1999).

$$
\text { DSRI }=\frac{\text { Receivables }_{t} / \text { Sales }_{t}}{\text { Receivables }_{t-1} / \text { Sales }_{t-1}}
$$

\section{Gross Margin Index (GMI)}

Gross margin index (GMI) merupakan rasio penjualan minus beban penjualan, general, dan administratif untuk penjualan pada tahun $t$ terhadap rasio yang sama di tahun t-1. Rumus untuk menghitung rasio GMI adalah sebagai berikut (Beneish, 1999).

$$
G M I=\frac{\left(\text { Sales }_{t-1}-\operatorname{COGS}_{t-1}\right) / \text { Sales }_{t-1}}{\left(\text { Sales }_{t}-\operatorname{COGS}_{t}\right) / \text { Sales }_{t}}
$$

\section{Asset Quality Index (AQI)}

Asset quality index (indeks kualitas asset) merupakan rasio noncurrent asset selain asset property, plant, equipment (PP\&E) berbanding dengan total asset. Semakin tinggi rasio maka semakin besar kemungkinan perusahaan melakukan penangguhan biaya. Berikut rumus perhitungan rasio AQI berdasarkan Beneish (1999).

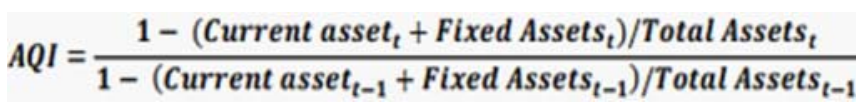

\section{Sales Growth Index (SGI)}

Sales growth index (index pertumbuhan penjualan) merupakan perbandingan antara penjualan tahun $\mathrm{t}$ dengan penjualan tahun $\mathrm{t}-1$. Berikut rumus perhitungan rasio SGI berdasarkan Beneish (1999).

$$
S G I=\frac{\text { Sales }_{t}}{\text { Sales }_{t-1}}
$$

\section{Depreciation Index (DEPI)}

Tingkat penyusutan pada tahun tertentu sama dengan depresiasi/(depresiasi + Net PP \& E). Rumus untuk menghitung rasio DEPI adalah sebagai berikut (Beneish, 1999).

$$
\text { DEPI }=\frac{\left[\text { Depreciation }_{t-1} /\left(\text { PPE }_{t-1}+\text { Depreciation }_{t-1}\right)\right]}{\left[\text { Depreciation }_{t} /\left(\text { PPE }_{t}+\text { Depreciation }_{t}\right)\right]}
$$

\section{Sales General and Administrative Expenses Index (SGAI)}

Rasio beban penjualan, general dan administratif untuk penjualan pada tahun $t$ terhadap rasio yang sama di tahun $\mathrm{t}-1$. Berikut rumus perhitungan rasio SGAI berdasarkan Beneish (1999).

$$
S G A I=\frac{S G A_{t} / \text { Sales }_{t}}{S G A_{t-1} / \text { Sales }_{t-1}}
$$

\section{Leverage Index (LVGI)}

Perbandingan rasio total utang dan total aktiva pada tahun $\mathrm{t}$ dengan rasio yang sama 
pada tahun t-1. Rumus untuk menghitung rasio LVGI adalah sebagai berikut (Beneish, 1999). $L V G I=\frac{\left[\left(\text { Current liabilities }_{t}+\text { Total long Term Debt }_{t}\right) / \text { Total Assets }_{t}\right]}{\left[\left(\text { Current liabilities }_{t-1}+\text { Total Long Term Debt }_{t-1}\right) / \text { Total Assets }_{t-1}\right]}$ dalam laporan keuangan memiliki nilai koefisien jalur sebesar 0,33 dan $\mathrm{P}$ value sebesar $\mathrm{P}<0.01$ yang artinya langkah pertama untuk pengujian hipotesis mediasi ini terpenuhi sehingga dapat dilanjutkan pada pengujian berikutnya.

\section{TATA}

Akrual dihitung sebagai perubahan akun modal kerja selain kas kurang depresiasi. Total akrual atau partisi total akrual digunakan dalam pekerjaan sebelumnya untuk menilai sejauh mana manajer membuat discretionary akuntansi pilihan untuk mengubah pendapatan sesuai yang diinginkan. Rumus untuk menghitung rasio TATA berdasarkan Beneish (2012) sebagai berikut.

$T A T A=\frac{\left(\text { Income Before Extraordinary Item }_{t}-\text { Cash flow from operation }_{t}\right)}{\text { Total Assets }}$

\section{HASIL}

Penelitian ini dilakukan di perusahaan manufaktur yang terdaftar pada Bursa Efek Indonesia selama tahun 2014 sampai dengan 2019. Terdapat 11 perusahaan manufaktur yang memenuhi kriteria untuk diteliti. Pengujian hipotesis dalam penelitian ini menggunakan analisis SEMPLS dengan menggunakan software WarpPLS 5.0. Pengujian hipotesis dalam penelitian menggunakan analisis jalur, karena penelitian ini tidak hanya menguji hubungan langsung saja, akan tetapi juga menguji hubungan tidak langsung. Berikut adalah hasil pengujian hipotesis penelitian ini.

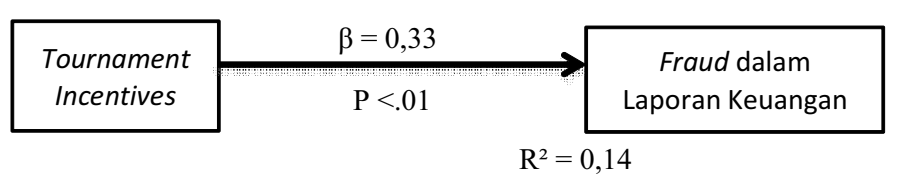

Gambar 1.1

Estimasi Hubungan Langsung (TI $\rightarrow$ FR)

Berdasarkan Gambar 1.1 dapat diketahui bahwa tournament incentives terhadap fraud $\mathrm{t}$

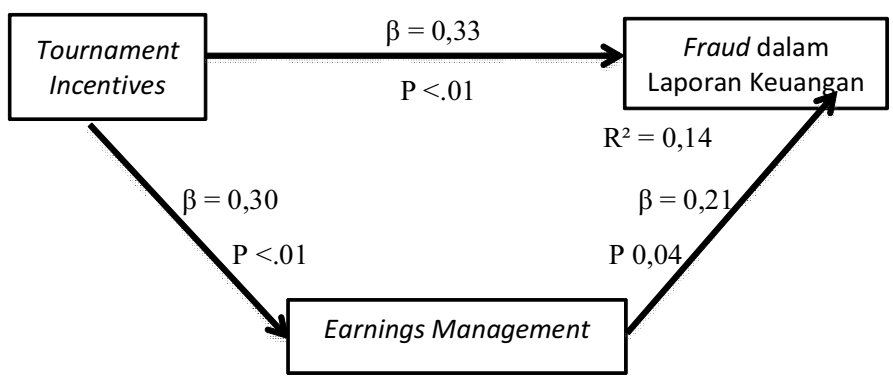

Gambar 1.2

Estimasi Hubungan Tidak Langsung (Full Model)

\section{Earnings Management}

Gambar 1.2 menunjukkan estimasi hubungan tidak langsung antara variabel tournament incentives terhadap fraud dalam laporan keuangan dengan earnings management sebagai variabel pemediasi. Berdasarkan gambar tersebut dapat diketahui bahwa variabel tournament incentives terhadap fraud dalam laporan keuangan memiliki nilai koefisien jalur yang positif yaitu $\beta=0,33$ dengan $\mathrm{P}<0,01$. Nilai koefisien jalur dari tournament incentives terhadap earnings management sebesar $\beta=0,30$ dengan $\mathrm{P}<0,01$ dan juga nilai koefisien jalur earnings management terhadap fraud dalam laporan keuangan sebesar $\beta=0,21$ dengan nilai $\mathrm{P}<0,05$.

Berdasarkan hasil pengujian tersebut dapat diketahui bahwa ketika hubungan langsung (lihat Gambar 1.1) dimasuki variabel mediasi dan nilainya masih tetap signifikan maka dapat dilanjutkan untuk pengujian berikutnya, yaitu melakukan perhitungan variance accounted for (VAF) melalui pembagian (/) antara total hubungan tidak langsung dengan hubungan total yang diperoleh dari penjumlahan $(+)$ antara hubungan 
Tabel 1.1

Hasil Penghitungan VAF Hubungan Langsung

\begin{tabular}{|c|c|c|}
\hline Hubungan Tidak langsung (G & & \\
\hline $\mathrm{TI} \rightarrow \mathrm{EM} \rightarrow \mathrm{FR}$ & $0,30 * 0,21$ & 0,063 \\
\hline Total Hubungan tidak langsung & & 0,063 \\
\hline Hubungan langsung & & \\
\hline $\mathrm{TI} \rightarrow \mathrm{FR}$ & & 0,33 \\
\hline Total Hubungan Langsung & & 0,33 \\
\hline Hubungan Total & $0,063+0,33=0,39$ & \\
\hline VAF $(\mathrm{TI} \rightarrow \mathrm{EM} \rightarrow \mathrm{FR})$ &  & 0,16 \\
\hline
\end{tabular}

langsung dengan tidak langsung. Jika nilai VAF $>$ 0,80 maka menunjukkan peran mediasi secara penuh dan jika nilai VAF berada di antara 0,20 hingga 0,80 maka peran mediasi hanya sebagian. Sedangkan ketika nilai VAF menunjukkan angka kurang dari 0,20 maka dapat disimpulkan bahwa hampir tidak terjadi efek mediasi dalam model (Hair dkk., 2014). Tabel 1.1 menyajikan hasil lengkap untuk perhitungan variance accounted for (VAF) tersebut.

Berdasarkan hasil pengujian VAF pada tabel tersebut dapat diketahui bahwa nilai pada hipotesis mediasi sebesar 0,16 , hal tersebut menunjukkan bahwa earnings management tidak mam- pu menyerap pengaruh langsung dari model mediasi.

\section{Pembahasan Hipotesis}

Tabel 1.2 merangkum hasil pengujian hipotesis penelitian ini. Hipotesis pertama yang berbunyi tournament incentives berpengaruh positif terhadap kemungkinan terjadinya fraud dalam laporan keuangan terdukung. Hal tersebut dapat dilihat dari nilai koefisien jalur dari $\mathrm{TI} \rightarrow \mathrm{FR}$ sebesar 0, 33 dan nilai $\mathrm{P}<0,01$. Hasil tersebut berarti bahwa semakin tinggi tournament incentives maka kemungkinan terjadi fraud dalam

Tabel 1.2

Rekapitulasi Hasil Pengujian Hipotesis

\begin{tabular}{|clcl|}
\hline Hipotesis & Hubungan & Koefisien Jalur & Keterangan \\
\hline $\mathrm{H} 1$ & TI $\rightarrow$ FR & $0,33^{* * *}$ & Terdukung \\
H2 & TI $\rightarrow$ EM & $0,30^{* * *}$ & Terdukung \\
H3 & EM $\rightarrow$ FR & $0,21^{* *}$ & Terdukung \\
H4 & TI $\rightarrow$ EM $\rightarrow$ FR & 0,16 & Tidak terdukung \\
\hline $\begin{array}{l}* * * \text {-value }<0,01 \\
* * \text {-value }<0,05\end{array}$ & & \\
\hline
\end{tabular}


laporan keuangan juga tinggi. Tournament incentives mendorong eksekutif untuk meningkatkan kinerjanya agar mampu mencapai insentif yang ditawarkan. Untuk mencapai target tersebut, tidak jarang para eksekutif melakukan tindakan menyimpang, seperti kecenderungan melakukan fraud dalam pelaporan keuangan sehingga dapat berakibat buruk bagi perusahaan. Hasil penelitian ini mendukung hasil penelitian yang dilakukan oleh (Jia 2018).

Hipotesis kedua dalam penelitian ini yaitu tournament incentives berpengaruh positif terhadap earnings management terdukung. Hal tersebut dapat dilihat dari nilai koefisien jalur TI $\rightarrow$ EM sebesar 0,30 dengan nilai $\mathrm{P}<0,01$. Hasil tersebut mengindikasikan bahwa semakin tinggi tournament incentives maka semakin tinggi pula kemungkinan seseorang untuk melakukan earnings management. Tournament incentives dapat menyebabkan kecenderungan kesalahan yang lebih tinggi dalam pelaporan keuangan, sehingga memungkinkan untuk melakukan tindakan earnings management ( $\mathrm{Haß}$ et al. 2015).

Hipotesis selanjutnya yaitu earnings management berpengaruh positif terhadap kemungkinan terjadinya fraud dalam laporan keuangan juga terdukung. Hal tersebut dapat dibuktikan dari nilai koefisien jalur dari $(\mathrm{EM} \rightarrow \mathrm{FR})$ sebesar 0,21 dan nilai $\mathrm{P}<0,04$. Hasil tersebut menunjukkan bahwa semakin tinggi earnings management maka semakin tinggi pula kemungkinan terjadinya fraud dalam laporan keuangan.

Hipotesis terakhir dalam penelitian ini tidak terdukung. Al tersebut dapat dilihat dari hasil penghitungan VIF (lihat Tabel 1.2) sebesar 0,16. Hasil tersebut menunjukkan bahwa earnings management tidak memediasi pengaruh tournament incentives terhadap kemungkinan terjadinya fraud dalam laporan keuangan. Hasil tersebut mengindikasikan bahwa earnings management tidak dapat menyerap pengaruh langsung tournament incentives terhadap kemungkinan terjadinya fraud dalam laporan keuangan.

\section{KESIMPULAN}

Penelitian ini bertujuan untuk menginvestigasi pengaruh dari tournament incentives terhadap earnings management dan fraud, serta dampak mediasi dari earnings management pada pengaruh tournament incentives terhadap fraud. Hasil penelitian ini dapat disimpulkan bahwa tournament incentives berpengaruh positif terhadap kemungkinan terjadinya fraud dalam laporan keuangan. Yang kedua tournament incentives berpengaruh positif terhadap earnings management. Selanjutnya earnings management berpengaruh positif terhadap kemungkinan terjadinya fraud dalam laporan keuangan. Yang terakhir earnings management tidak memediasi pengaruh tournament incentives terhadap kemungkinan terjadinya fraud dalam laporan keuangan.

\section{DAFTAR PUSTAKA}

Bebchuk, Lucian A., K.J. Martijn Cremers, and Urs C. Peyer. 2011. "The CEO Pay Slice." Journal of Financial Economics 102(1): 199-221.

Chena, Joseph, Harrison Honga, and Jeremy C. Stein. 2001. "Forecasting Crashes: Trading Volume, Past Returns and Conditional Skewness in Stock Prices." Journal of Financial Economics 54(6): 2143-84.

Haß, Lars Helge, Maximilian A. Müller, and Skrålan Vergauwe. 2015. "Tournament Incentives and Corporate Fraud." Journal of Corporate Finance 34: 251-67. http:// dx.doi.org/10.1016/j.jcorpfin.2015.07.008. 
Jia, Ning. 2018. "Tournament Incentives and Stock Price Crash Risk." Accounting Horizons 32(3): 101-21.

Kim, Jeong Bon, Zheng Wang, and Liandong Zhang. 2016. "CEO Overconfidence and Stock Price Crash Risk." Contemporary Accounting Research 33(4): 1720-49.

Kini, Omesh, and Ryan Williams. 2012. "Tournament Incentives, Firm Risk, and Corporate Policies." Journal of Financial Economics 103(2): 350-76. http://dx.doi.org/ 10.1016/j.jfineco.2011.09.005.

Kubick, Thomas R., and Adi N.S. Masli. 2016. "Firm-Level Tournament Incentives and Corporate Tax Aggressiveness." Journal of Accounting and Public Policy 35(1): 66-83. http://dx.doi.org/10.1016/ j.jaccpubpol.2015.08.002.

Lazear, Edward P., and Sherwin Rosen. 2002. "Rank-Order Tournaments as Optimum Labor Contracts." Journal of Political Economy 89(5): 841-64.
Rediker, Kenneth J. 1995. "I- MECHANISMS.” 16(July 1992): 85-99.

Sun, Sophia Li, Ahsan Habib, and Hedy Jiaying Huang. 2019. "Tournament Incentives and Stock Price Crash Risk: Evidence from China." Pacific Basin Finance Journal 54(September 2018): 93-117. https:// doi.org/10.1016/j.pacfin.2019.02.005.

$\mathrm{Xu}$, Yuehua, Lin Zhang, and Honghui Chen. 2018. "Board Age and Corporate Financial Fraud: An Interactionist View.” Long Range Planning 51(6): 815-30. https:// doi.org/10.1016/j.lrp.2017.08.001.

Yiu, Daphne W., Yuehua Xu, and William P. Wan. 2014. "Corporate Financial Fraud." Organization Science 25(5): 1549-71.

Zhang, Xiaomeng et al. 2008. "Ceos on the Edge: Earnings Manipulation and StockBased Incentive Misalignment.” Academy of Management Journal 51(2): 241-58. 